\title{
TOURIST EXPERIENCE AS THE BASIS FOR DESTINATION COMPETITIVENESS: A CASE STUDY OF OHRID
}

\author{
Simonida Vilić \\ Tatjana Dujaković
}

University for Business Studies,

Banja Luka, Bosnia and Herzegovina
Correspondence:

Simonida Vilić

e-mail:

svilic26@yahoo.com

\begin{abstract}
:
Since the habits and preferences of customers are constantly changing, the existing and new tourism destinations are increasingly competing to find new ways to attract tourists and remain competitive in the market. Quality improvement has become an imperative in creating a strategy for achieving the destination competitiveness. This improvement is based on tourism experience acquired during the visit and the first impression of the destination created in the minds of consumers. This paper aims to explore how tourism experience affects the awareness of consumers and their perception of destination competitiveness.
\end{abstract}

Keywords:

tourism experiences, destination competitiveness, tourism satisfaction.

\section{INTRODUCTION}

At the global tourism market, tourism destination is a fascinating and intriguing concept. In tourism industry, competition among territorial areas is usually not centered on the single aspects of the tourism product (environmental resources, transportation, tourism services, hospitality etc.), but on the tourism destination as an integrated set of facilities for tourists (Buhalis \& Foerste, 2015). Competitiveness is the ability to increase tourism expenditure, to attract a vast number of visitors while providing them with satisfying, memorable experiences and in a profitable way, while enhancing the wellbeing of destination residents and preserving the natural capital of the destination for future generations (Ritchie \& Crouch, 2012).

Due to the different nature of destinations or the purpose/types of tourism activities, it is difficult to measure, evaluate, and compare destinations, as in many cases they are unique in their features and cannot be considered identical (Prebensen et al., 2014). Therefore, if we analyze the competitiveness of tourism destinations, it is necessary to investigate the level of satisfaction of visitors and the quality of tourism experience as a paradigm of destination competitiveness development in the global tourism market. This concept is imperative because there is a strong link between satisfaction and repeat purchasing behavior, consumer loyalty, switching behavior, complaining behavior, word-of-mouth recommendation, revenue and profits (Vasilevich \& Czetyrbok, 2015). The experience is an inward state of an individual, triggered by phenomena a person encountered, endured and experienced (Cohen \& Cohen, 2012). According to Middleton and Clarke (2012), the overall tourism offer might be defined 
in terms of five main components: destination attractions, destination facilities and services, accessibility of the destination, images, brands and perceptions, price to the visitor. Thus, many destinations are trying to offer an unforgettable experience to tourists with a service of superior quality whose synergies will provide the highest level of satisfaction and exceed the expectations of tourists. Baker and Crompton (2000) define satisfaction as the tourist's emotional state after experiencing the trip while Oliver (2012) concluded that tourism satisfaction is based on the coincidence of the expectations tourists have before visiting the destination and the results of experiences achieved at the destination i.e., a comparison between the previous image the tourist had about the destination and the one based on what he/she sees, feels and remembers about the destination.

The goal of every tourism destination is to offer unique, extraordinary and memorable tourism experiences to target tourists so as to maintain a sustainable competitive advantage. In order to meet the expectations of tourists in the best possible way, it is necessary for a destination to constantly explore the attitudes and perceptions of tourists. The analysis of tourists' at titudes, their behavior and emotional experience of a destination, as well as the assessment of the complete experience of tourists after visiting destinations are the basis for creating a branding strategy destination and increasing its competitiveness. Creating a respectable and modern destination brand, and tourist stamps, affirmation and evolution of its competitive identity and external reputation, is a tool of strategic destination management.

The main objective of this study is to assess the first impression that visitors have of the area and analyze the key attributes which should lead to improving the quality of the overall tourist experience, and therefore tourist satisfaction, the construction of a loyal relationship with tourists and increasing the destination competitiveness. The paper analyzes the results of the conducted research on the perception that tourists have of the city of Ohrid as a tourism destination. The research led to clear indicators that also reflect the attitudes and preferences of tourists who visited the city of Ohrid, what makes it unique and attractive for tourist trips, and which elements constitute its unique brand identity.

\section{RESEARCH METHODOLOGY}

In the previous part of the paper, methods of description and analysis were used, while the test method was used for collecting primary data. A questionnaire was used for the implementation of field research as a tool to use testing methods. The selection of respondents was random, and the sample included 73 respondents from Bosnia and Herzegovina during the period May June 2016. The survey was conducted at the destination.

\section{RESEARCH RESULTS AND DISCUSSION}

The demographic data showed that out of 73 respondents who provided gender information, 50.7\% were male, while $49.3 \%$ were female. As for the age structure of the respondents, the two most dominant groups were young adults (35.6\%) or those middle-aged (23.3\%). Most of the respondents were married (47.9\%). Data on the level of education of respondents indicate that $34.2 \%$ of the respondents had secondary education and $17.8 \%$ of the respondents possess graduate and postgraduate education.

As for the answer to the question concerning the frequency of visits to the city of Ohrid, we can see that $64.4 \%$ of tourists visited the city of Ohrid 3-5 times. This data show that destination managers must work towards promoting tourism in a way that will attract new visitors and encourage them to come back. The average duration of stay of the largest number of tourists (49.3\%) in Ohrid included at least one week.

With sources of information that encouraged the decision about travel, the respondents were able to choose among various answers, of which most relevant are:

- The recommendations of friends, colleagues or relatives as very good promoters of tourism, since $38.9 \%$ of tourists listened to them while taking a decision. The results indicate the strength of word-of-mouth communication.

- Satisfaction during the previous visit to destination was crucial for the decision of $19.4 \%$ of tourists to revisit the city of Ohrid, which indicates that the tourists return to destinations that manage to respond to their demands and expectations.

- It is indicative of the number of tourists who are informed about the city of Ohrid via the Internet and $40.3 \%$ of them confirm that a good Internet presentation can attract potential tourists.

As regards the period or season in which the respondents decided to travel to Ohrid, the highest percentage of respondents, namely $37.5 \%$, visited Ohrid during the summer. Similarly, $36.6 \%$ of respondents visited this city in spring. The data show that the main reason to visit Ohrid is of purely tourist nature (57.8\%). The data show that most tourists come to visit certain desti- 
nation because of some event organised there (60.6\%). This high percentage clearly shows how the city of Ohrid is a very attractive destination, with well organized activities, including cultural, sporting and entertainment events that attract the attention of potential tourists.

Tourist experience represents the basic mechanism for successful management of destination competitiveness. Experience is gained during the stay of tourists and if positive, it may substantially determine the decision to come back. By analyzing the reasons why tourists would revisit Ohrid, it can be noticed that the two most dominant responses are the quality of rest (43.1\%) and natural beauty of the destination (30.6\%). The answer to this question is clear evidence that Ohrid gives a specific sense of peace and well-being, both spiritual and physical. The data in Figure 1 show that the largest percentage of tourists gave the highest evaluation of the tourist offer of Ohrid, which indicates that tourists recognized the diversity and quality of the destination.

Ohrid has a very rich and diverse historical and cultural heritage. Given the cultural and religious differences and changes, it is a miracle that so many historical sites have been preserved up to the present. There are over 50 thousand people of different religious affiliations and nationalities that live in peace and coexistence in Ohrid (Balabanov, 2010). Tourists can feel this harmony and always come back to at least briefly stop time and enjoy the moment. Special interest of tourists is the way in which culture, tradition and history are linked. This is the reason why the highest percentage of respondents, i.e., $87.5 \%$ of them assigned highest rates to cultural and historical attractions. Also, the highest percentage of tourists, i.e., $97.2 \%$, assigned highest rates to the natural sights of Ohrid. The reason for this lies in the fact that Lake Ohrid is over three million years old and is a rather fascinating destination, which supplies fresh and clean water that is healthy to drink, which is nowadays a real rarity (Deliso, 2007). In the next part of the questionnaire, tourists had the task to assess the extent to which they agree with these views, on the 1-5 scale (from $1=$ insufficient to $5=$ excellent). In this way, guests are appraised accommodation facilities, cultural and historical attractions, compliance and quality of service prices, the local culinary offer, hospitality and kindness of the local people, the uniqueness of cultures and customs, nightlife and entertainment, local infrastructure, availability of tourism information, landscapes / natural attractions and non-contamination of the environment. The answers to these questions are illustrated in Table 1.

Tourists strongly agree that the top four core values of Ohrid as a destination are: landscapes / natural attractions $95.8 \%$, unpolluted life environment $89.7 \%$, offer of cultural and historical attractions $88.9 \%$ and hospitality and kindness of the local population $88.7 \%$. It should be pointed out that none of the interviewed tourists rated negatively any of the key attributes. The data indicate that tourists recognized Ohrid as a destination with unpolluted natural resources, diverse cultural and historical heritage and hospitable population.

The final point of the research was to analyze the entire emotional experience of tourists who visited Ohrid, where the largest percentage of tourists, i.e. $77.8 \%$ characterized this destination as a wonderful experience filled with beautiful and positive emotions.

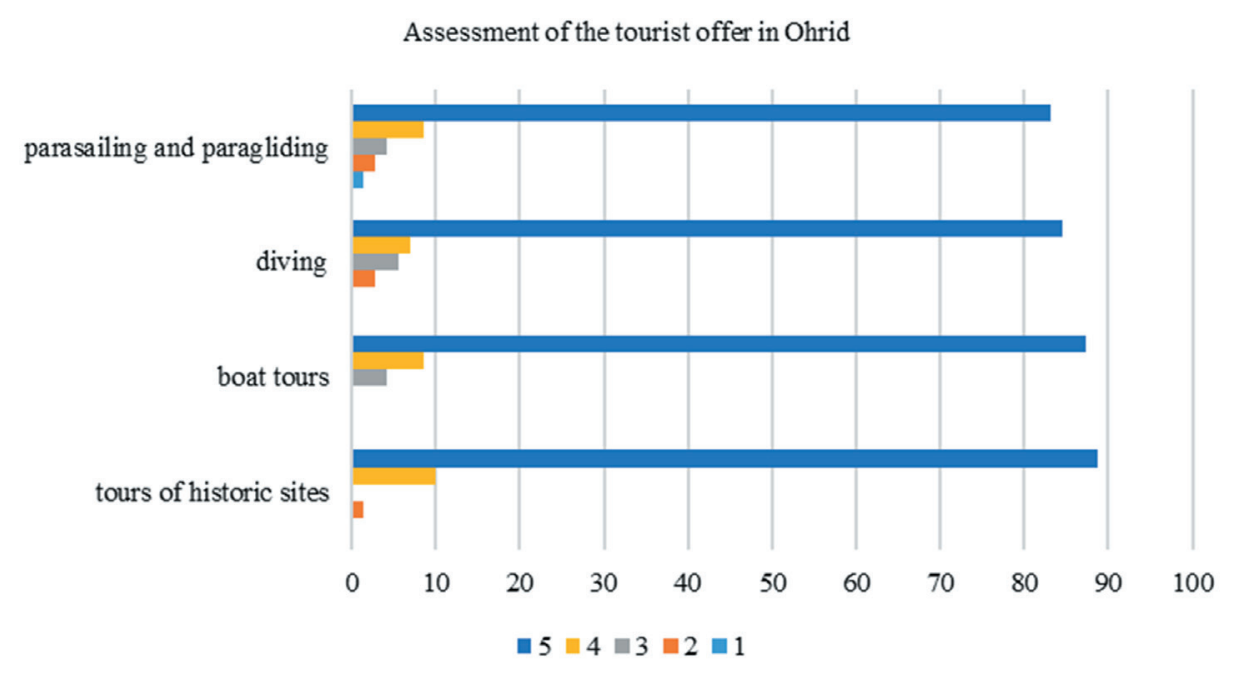

Figure 1. Assessment of the tourist offer in Ohrid 
Table 1. Key attributes of the city of Ohrid

\begin{tabular}{|c|c|c|c|c|c|c|}
\hline \multirow{2}{*}{ No. } & \multicolumn{6}{|c|}{ Key attributes of the city of Ohrid } \\
\hline & Evaluation & Excellent & Verygood & Good & Weak & Insufficient \\
\hline 1 & Quality of accommodation facilities & $75 \%$ & $22.2 \%$ & $2.8 \%$ & $0 \%$ & $0 \%$ \\
\hline 2 & Offer of cultural and historical attractions & $88.9 \%$ & $11.1 \%$ & $0 \%$ & $0 \%$ & $0 \%$ \\
\hline 3 & Compliance of quality services and prices & $66.2 \%$ & $25.4 \%$ & $7 \%$ & $1.4 \%$ & $0 \%$ \\
\hline 4 & Rating the local gastronomic offer & $87.5 \%$ & $6.9 \%$ & $5.6 \%$ & $0 \%$ & $0 \%$ \\
\hline 5 & Hospitality and kindness of the local population & $88.7 \%$ & $9.9 \%$ & $1.4 \%$ & $0 \%$ & $0 \%$ \\
\hline 6 & Uniqueness of cultures and customs & $87.5 \%$ & $9.7 \%$ & $2.8 \%$ & $0 \%$ & $0 \%$ \\
\hline 7 & Nightlife and entertainment & $73.6 \%$ & $18.1 \%$ & $8.3 \%$ & $0 \%$ & $0 \%$ \\
\hline 8 & Local infrastructure & $67.2 \%$ & $26.9 \%$ & $4.5 \%$ & $1.4 \%$ & $0 \%$ \\
\hline 9 & Availability of useful tourist information & $72.2 \%$ & $20.8 \%$ & $5.6 \%$ & $1.4 \%$ & $0 \%$ \\
\hline 10 & Landscapes / natural attractions & $95.8 \%$ & $2.8 \%$ & $1.4 \%$ & $0 \%$ & $0 \%$ \\
\hline 11 & Unpolluted life environment & $89.7 \%$ & $8.8 \%$ & $1.5 \%$ & $0 \%$ & $0 \%$ \\
\hline
\end{tabular}

\section{CONSLUSION}

In today's highly competitive market, the destination's survival depends greatly on its ability to provide superior tourist experience, which generates tourist satisfaction. Every manager who wishes to gain advantage in terms of providing high-quality tourist experience must recognize what tourists want and correctly assess the importance that tourists attach to individual elements that make up the overall tourist experience. The findings of this paper indicate that the quality of tourism experience has a strong influence on tourists' perception of destination competitiveness. This means that if tourists experience high-quality tourism experience filled with positive emotions and enthusiasm, it shall be deemed that such destinations are better and more competitive than other destinations and they will gladly visit such destinations again.

Tourism destination must be able to anticipate the needs of tourists and to properly fulfill their requirements as destination competitiveness is directly related to tourists' expectations, activities, experiences and satisfaction. Tourism experience that includes the personal experience of natural and cultural resources of destinations, tourist activities, nightlife and entertainment, quality of accommodation, hospitality and interact with the local population and consumption of local specialties, creates the perception of tourists and emotions associated with the destination, and thus directly affect the competitiveness of the destination. Therefore, it is important that tourism destinations offer provides an opportunity for tourists to be involved and learn about the local history, culture, authentic local food and cuisine, languages and local lifestyles which may further add value to their experiences. Destination managers/marketers need to pay special attention to the quality of on-site experience. Also, managers / marketers need to focus on the active promotion of the destination that will enable them to create a positive image of the destination and highlight its unique attributes, so as to encourage tourists to visit the target destination and personally convinced of the richness of its offer. The analysis of the research indicates that if managers/marketers want to increase the level of perceived competitiveness of destinations in the minds of tourists, it is necessary to generate a serious and attractive tourist offer, which will provide an unforgettable experience of high quality from the very beginning of the journey to the very end, filled with wonderful memories that will always remind tourists of the destination they visited and encourage them to visit it again. The tourism offer created in such a manner focuses on the delivery of a memorable and high quality tourism experience that tourists will consider unique and such destination will be perceived superior and more competitive than others.

\section{REFERENCES}

Baker, D. A., \& Crompton, J. L. (2000). Quality, satisfaction and behaviour intentions. Annals of Tourism Research, 27(3), 785-804. doi:10.1016/S01607383(99)00108-5

Balabanov, K. (2010). Ohrid. Skopje: Matica makedonska Skopje. 
Buhalis, D., \& Foerste, M. (2015). SoCoMo Marketing for Travel and Tourism: empowering co-creation of value. Journal of Destination Marketing \& Management, 4(3), 151-161. doi:10.1016/j.jdmm.2015.04.001

Cohen, E., \& Cohen, S.A. (2012). Current sociological theories and issues in tourism. Annals of Tourism Research, 39(4), 2177-2202. doi:10.1016/j.annals.2012.07.009

Deliso, C. (2007). Hidden Macedonia: The mystic lakes of Ohrid and Prespa. London: Haus.

Middleton, V.T.C., \& Clarke, J. (2012). Marketing in Travel and Tourism. London: Routledge.
Oliver, R. (2012). Satisfaction: A Behavioral Perspective on the Consumer. London: Routledge.

Prebensen, N., Chen, J., \& Uysal, M. (2014). Creating Experience Value in Tourism. Boston: CABI Publishing.

Ritchie, J.R.B., \& Crouch, G. (2012). Competitiveness and Tourism. Massachusetts: Edward Elgar Publishing.

Vasilevich, P., \& Czetyrbok, C. (2015). Consumer Psychology of Tourism, Hospitality and Leisure. Arcler Press LLC. 